\title{
Design of Metal MUMPs based LLC Resonant Converter for On-chip Power Supplies
}

\author{
Fahimullah Khan ${ }^{1, a}$, Yong Zhu, 1, b Junwei Lu, ,c, ,Dzung Dao, 1,d \\ ${ }^{1}$ Queensland Micro \& Nanotechnology Centre \\ Griffith University, Nathan, Australia \\ a fahimullah.khan@griffithuni.edu.au \\ by.zhu@griffith.edu.au \\ ci.lu@griffith.edu.au \\ d.dao@griffith.edu.au
}

\begin{abstract}
In this paper, a novel Metal MUMPs based tunable LLC converter is proposed for on chip power supplies applications. The design is optimized at $20 \mathrm{MHz}$ resonant frequency of LLC tank network and MEMS based tunable capacitor is fabricated on the chip to tune the peak resonance frequency of circuit due to the variation of load. The Design is simulated in FEM based numerical software COMSOL and Intellisuite. From the analysis a magnetizing inductance of $14 \mathrm{nH}$ a leakage inductance of $48 \mathrm{nH}$ has been achieved from $3.6 \mathrm{~mm}^{2}$ rectangular coil transformer. The total capacitance of $1300 \mathrm{pF}$ has been achieved from parallel plate capacitor and variation of $3 \mathrm{pF}$ has been achieved from tunable capacitor. The passive components on LLC tank network have been fabricated on the same chip.
\end{abstract}

Keywords—resonant tank network; Intellisuite; magnetizing inductance;Leakage inductance;COMSOL

\section{INTRODUCTION}

With the advent of resonant power converters many of the problems of pulse width modulation converters (PWM) have been solved. The main problem in high frequency converters is the high switching loss in converters. In resonance converters the switches are softly commutated, therefore the switching loss can be easily reduced and this can also reduce the size of magnetic components by increasing frequency. Traditionally, resonant converter includes series resonant converter (SRC), parallel resonant converter (PRC) and series parallel resonant (SPRC) converters. The problem with series resonant converter is that at light load switching frequency has to increase in order to keep the output voltage regulated. In parallel resonant converter (PRC) circulating energy is much higher even at light load or no load. In series parallel resonant converter (SPRC) the main problem is the wide input range, which leads to high conduction and switching loss at high frequencies.

The LLC resonant converter [1] is a popular topology for its advantages over other resonant converters. It can regulate output voltage over wide line and load variations and with small variation in frequency. It can also achieve zero voltage switching (ZVS) over entire range of operation. It can be used in wide range of applications such as mobile phones with switched mode power supplies increase battery life. Similarly it can be used in implantable medical devices in human body [2] and can provide power to sensors and actuators in the systems efficiently. Also, it can provide efficient power supply from small solar panel to sensors in wireless sensor network. It can be used as DC-DC converter in power management ICs for micro scale robots for handling the variety of input voltages and supplying power for both actuators and control circuitry.

A lot of research has been done on LLC converters and many designs of LLC have been presented in [3] and [4] and the performance and behavior are completely analyzed. LLC resonant converter is implemented by using half-bridge MOSFETs in zero voltage switching (ZVS) condition and keeping voltage regulation at the output even at no load. So far no research has been done on LLC converter on chip implementation. This is the basic requirement of power supplies on chip. Similarly the load variation also shifts the peak resonance frequency of tank circuit. Thus, the input voltage frequency should vary with the variation of load to achieve regulated output.

Several integrated inductors have been presented for DCDC converters in [5] and their performances have been compared with a specially designed and fabricated $10 \mathrm{MHz}$ inductor. Furthermore, the prototype is tested with a commercially available $8 \mathrm{MHz}$ buck converter.

Many designs of on chip transformers have been presented in [6] for DC-DC converters having different dimensions, shapes, and core materials. The racetrack shape microtransformer has been presented in [7] with voltage gain of -1 $\mathrm{dB}$ between $1-20 \mathrm{M} \mathrm{Hz}$ frequency range. The turn ratio of transformer is $4: 4$ with dimension of $2.1 \mathrm{~mm} \times 11.3 \mathrm{~mm}$. Similarly integrated air core transformer is presented in [8]. The transformer is silicon-embedded and coreless for DC-DC conversion while optimized at $50 \mathrm{MHz}$ with the total size of 2 $\mathrm{mm}^{2}$. Several power supplies on chip (PwrSoC) and power supplies in package (PwrSiP) have been presented in $[9,10,11]$ and it is investigated that PwrSoC and PwrSiP have a higher power density than the conventional power modules.

In this paper, a new integrated LLC converter having tunable capacitor and micro-transformer has been proposed for 
power supplies on chip applications. The tunable capacitor is used to tune the resonant frequency of resonant tank with respect to the change in load in order to maintain voltage regulation. The design is optimized using finite element method (FEM) analysis software, Intellisuite and COMSOL. The electromechanical tuning capacitor has been simulated in MEMS specialized Intellisuite software whereas the magnetic component micro-transformer has been simulated using $\mathrm{AC} / \mathrm{DC}$ module of COMSOL. The prototype is implemented in MEMS standard process, Metal MUMPs from MEMSCAP which is low cost and commercially available.

\section{PROPOSED DESIGN}

The LLC resonant converter has three main parts as shown in fig.1. The switching part consists of MOSFETs, Q1 and Q2 which is used to produce a unipolar square-wave voltage, $\mathrm{V}_{\mathrm{d}}$. The second part is resonant circuit. The resonant network consists of resonant capacitance, $\mathrm{C}_{\mathrm{r}}$ and two inductances Leakage inductance, $\mathrm{L}_{\mathrm{r}}$ and Magnetizing inductance, $\mathrm{Lm}$. The third part is rectifier circuit on the secondary side. The four diodes connecting in bridge make a full wave rectifier to convert the AC signal into DC signal which is supplied to the load.

The energy in the resonant circuit circulates in the tank circuit and a part of it is delivered to the load through transformer as shown in fig. 1. In proposed design these passive elements are integrated on the same chip with the extremely reduced size of transformer makes the converter for portable devices and wireless energy transmission for biomedical sensors.

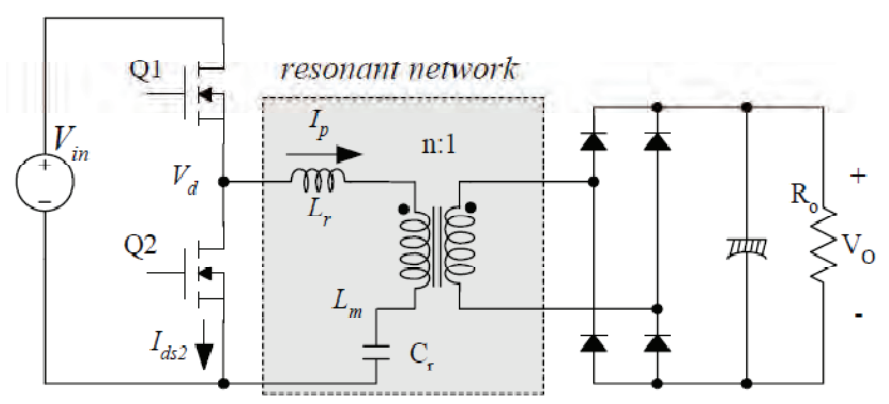

Fig 1. LLC resonant converter.

In the proposed design the resonant tank network is integrated on same die with the ability to tune the resonant frequency of the tank network as shown in fig.2. Thus it can overcome the problem of shifting of resonant frequency due to the variation of load at the output side. The resonant frequency of tank network is governed by two inductances and a capacitor. The resonance frequency is calculated by following equations.

$$
f_{1}=1 / 2 \pi \sqrt{L_{l k} C}
$$

$$
f_{2}=1 / 2 \pi \sqrt{\left(L_{m}+L_{l k}\right) C}
$$

It is noted from the design procedure given in [4] that higher peak voltage gain is obtained by reducing $L_{n}$ value in eq.4. where $L_{n}=\frac{L_{m}}{L_{l k}}, n$ is transformer turn ratio, $f_{o}$ is resonance frequency and $R_{L}$ is load.

$$
\begin{aligned}
& \mathrm{M}_{\mathrm{g}}=\left|\frac{\left(j \omega L_{m}\right) \| R_{e}}{\left(j \omega L_{m}\right) \| R_{e}+j \omega L_{r}+\frac{1}{j \omega C_{r}}}\right| \\
& Q=\frac{L_{m}\left(n^{2} R_{L}\right)}{2 \pi f_{0} L_{n}}
\end{aligned}
$$

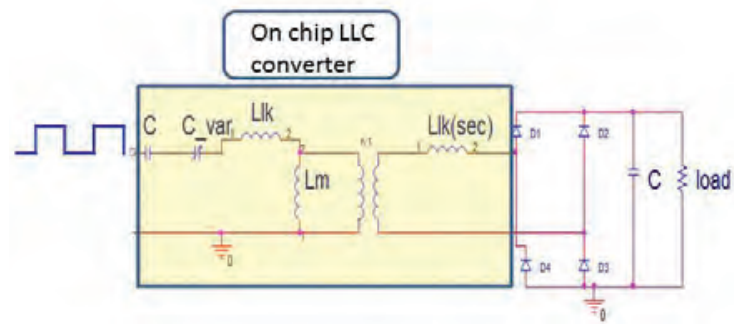

Fig 2. Integrated LLC resonant converter.

The design of LLC converter is optimized by following guide lines mentioned in [3-4] and parameters of resonant tank network are calculated from the eq.(1) and(2). The first resonance frequency which arises from the leakage inductance is about $20 \mathrm{MHz}$ and the second resonance frequency which arises due to the sum of leakage and magnetizing inductance is about $14.35 \mathrm{MHz}$. The values of circuit parameters are shown in table 1 .

Table1

\begin{tabular}{|l|l|}
\hline Tank circuit parameters & Obtained parameter value \\
\hline Capacitance, $\mathrm{C}$ & $1300 \mathrm{pF}$ \\
\hline Leakage inductance, $L_{l k}$ & $48 \mathrm{nH}$ \\
\hline Magnetizing Inductance, $L_{m}$ & $14.0 \mathrm{nH}$ \\
\hline Turn ratio & $1: 1$ \\
\hline
\end{tabular}

Fig.3 shows the layout of LLC resonant converter. The transformer has 1/1 turn ratio with NiZn ferromagnetic material glued at the top as illustrated in fig.4. A fixed capacitor and a variable capacitor are fabricated on same chip to achieve total capacitance of about $1300 \mathrm{pF}$. The variation in the capacitance is about $3 \mathrm{pF}$ which can bring about $20 \mathrm{kHz}$ change in frequency. 


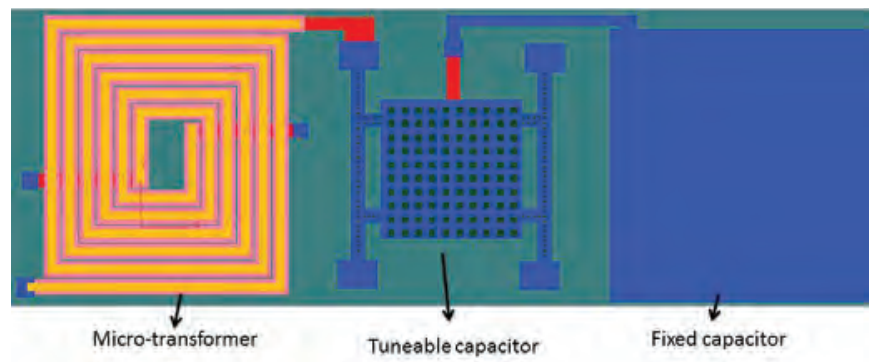

Fig 3. Layout of LLC resonant converter in Blueprint.

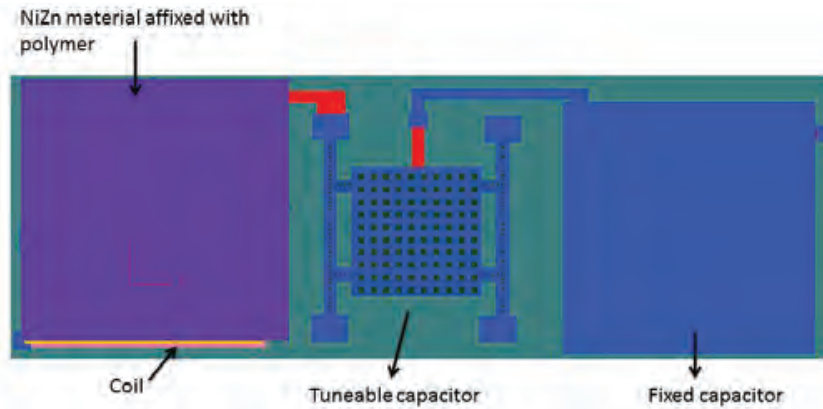

Fig 4. NiZn ferromagnetic material glued on top of transformer.

\section{FABRICATION PROCESS}

The design is optimized in commercially available low cost Metal MUMPs process and simulated in Fab viewer module of Intellisuite. After simulation, 3D model has been built to validate the structure and fabrication accuracy. The step-bystep process is shown in fig. 5

In Metal MUMPs process the base wafer is N-type silicon and a $2 \mu \mathrm{m}$ silicon dioxide $\left(\mathrm{SiO}_{2}\right)$ is grown to provide electrical isolation from substrate. A $0.5 \mu \mathrm{m}$ phosphosilicate glass (PSG) layer which acts as sacrificial layer is grown and patterned by photolithography process with the first mask layer as shown in fig. $5 \mathrm{c}$ ). The nitride1 layer with $0.35 \mu \mathrm{m}$ thickness is deposited and patterned with combination of nitride 2 layer. The purpose of nitride layers is to provide a protective encapsulation for the polysilicon as shown in fig.5(e). Fourth layer which is polysilicon film is $0.7 \mu \mathrm{m}$ thick for electrical cross-over routing, shown in fig.5(d). After polysilicon nitride 2 is deposited, this is patterned with the same nitride 1 mask layer. The sixth layer is oxide 2, which is $1.1 \mu \mathrm{m}$ of PSG which is released at the final release step to free the mechanical layer of Nickel. Anchor metal is the $7^{\text {th }}$ deposition layer which provides anchors for the metal structure. The metal layer is $20 \mu \mathrm{m}$ of electroplated patterned nickel layer and $0.5 \mu \mathrm{m}$ gold layer is plated on top of nickel to provide electrical contact pads for wire bonding as shown in fig.5 (i). The last layer is $1-3 \mu \mathrm{m}$ thick gold layer which can be plated on sidewall of metal layer to provide low electrical contact resistance. In the proposed design micro-transformer turns are obtained from the same layer.
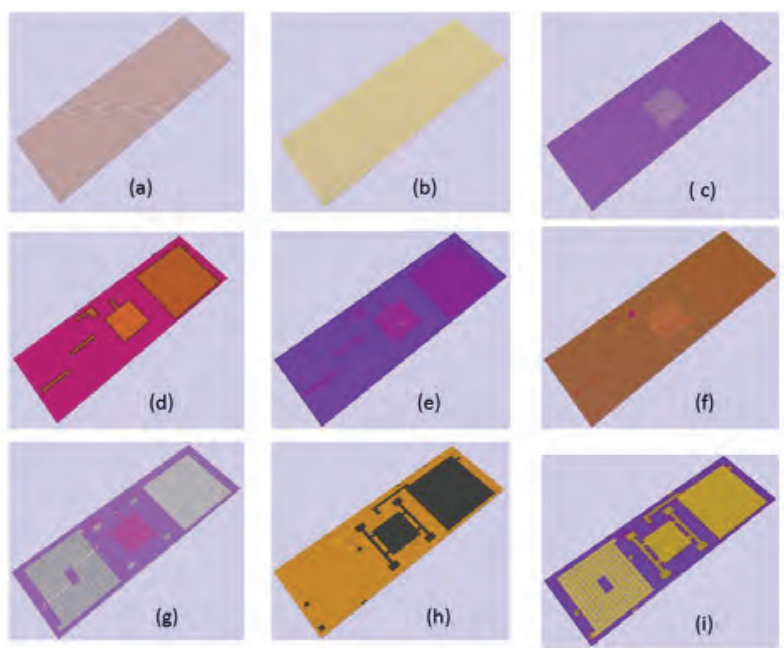

Fig 5. Step by Step fabrication process.

Finally, powder NiZn ferromagnetic material is mixed with polymer and glued at the top of transformer to provide a transformer core only at the top.

\section{Design Simulation}

\section{A. Transformer design simulation}

The proposed transformer is simulated using $3 \mathrm{D}$ AC/DC module of COMSOL $4.3 \mathrm{v}$. The magnetizing inductance and leakage inductance of transformer has been simulated using and open and short circuiting of transformer secondary coil. Figs.6, and 7 respectively shows the magnetizing and leakage inductance between $1 \mathrm{MHz}$ to $20 \mathrm{MHz}$.

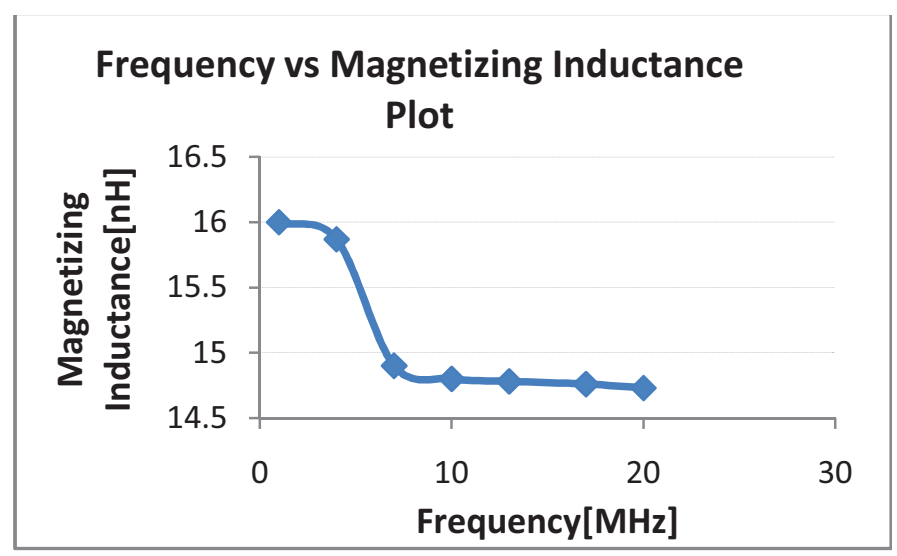

Fig. 6. Mutual inductance vs frequency.

The design is optimized at $20 \mathrm{MHz}$ and the simulation results shows mutual inductance of $14.6 \mathrm{nH}$ and leakage inductance of about $48.0 \mathrm{nH}$ are obtained from the 1/1 ratio transformer with a magnetic core on top of gold coils. 
Fig. 8 shows the volume plot of magnetic magnetic flux density. It is noted from the figure that magnetic flux density is maximum at the primary coil and covers the secondary side coil which is beside the primary coil. Furthermore, the maximum flux density is at the center of transformer.

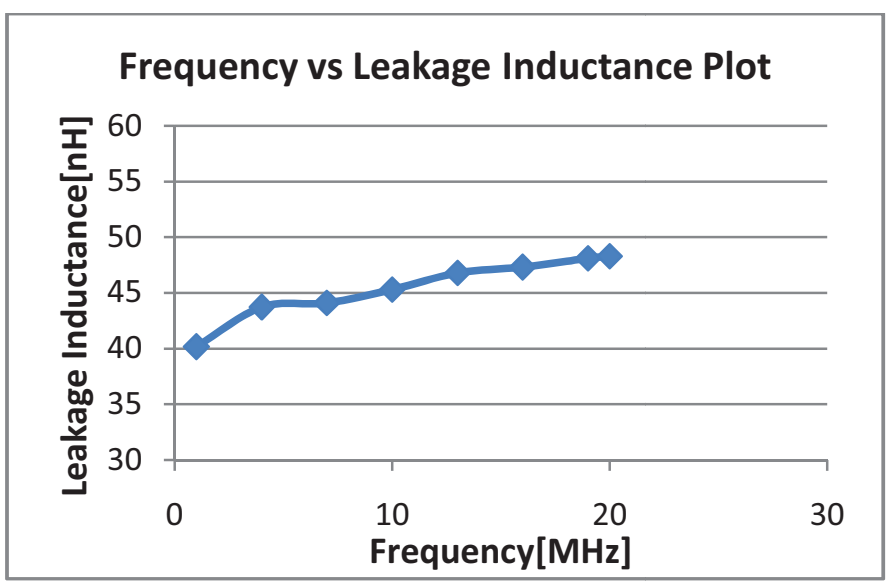

Fig.7. Leakage inductance vs frequency .

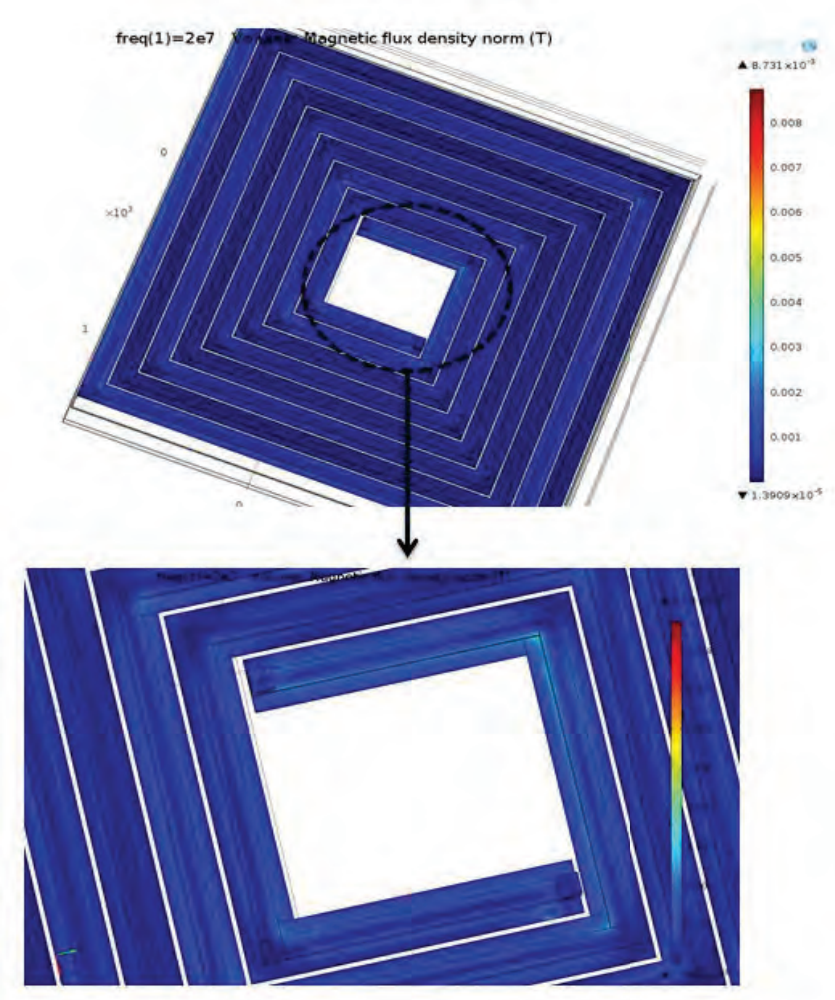

Fig.8 Volume plot of magnetic flux density at $20 \mathrm{MHz}$

\section{B. Variable Capacitor Simulation}

An H-type suspension tunable capacitor is fabricated on the same substrate with micro-transformer and fixed capacitor. The structure of in tunable capacitor is such that to restrict the motion of parallel plate in x-axis and y-axis and allow only in $\mathrm{z}$-axis displacement under the applied DC voltage to both the plate. The gap between the $\mathrm{Ni}$ metal and the nitride layer is $1.1 \mu \mathrm{m}$ as shown in fig.9. The natural frequency of tunable capacitor is $1.707 \mathrm{KHz}$ which is well below input signal $(20 \mathrm{MHz})$ to avoid resonance.

The displacement versus voltage plot is shown in fig.10. It is noted that the curve is almost linear uptil $10.5 \mathrm{~V}$. After $10.5 \mathrm{~V}$ an abrupt change in displacement is noted due to pull-in voltage which is given by following equation. It is noted that pull in effect starts at $10.4 \mathrm{~V}$ with remaining gap of $0.72 \mu \mathrm{m}$ between two plates.

$$
V_{p}=\sqrt{8 k d_{0}^{3} / 27 \epsilon A}
$$

Here $k$ is the spring constant of beams, $d_{o}$ is the gap between the parallel plate capacitor, $\epsilon$ is the permittivity of free space and ' $A$ ' is the area of parallel plate capacitor.

The total stiffness of the tunable capacitor is calculated through the mechanical deformation of spring coil of tunable capacitor as given in equation (6).

$$
K=4(K 1 K 2 / K 1+K 2)
$$

Where $K 1$ and $K 2$ is the series combination of cantilever beams as shown in fig. 9. The mechanical spring constant of cantilever beam is given by equation. (7) and (8).

$$
\begin{aligned}
& K_{1}=E w_{1} t^{3} / 4 l_{1}^{3} \\
& K_{2}=E w_{2} t^{3} / 4 l_{2}{ }^{3}
\end{aligned}
$$

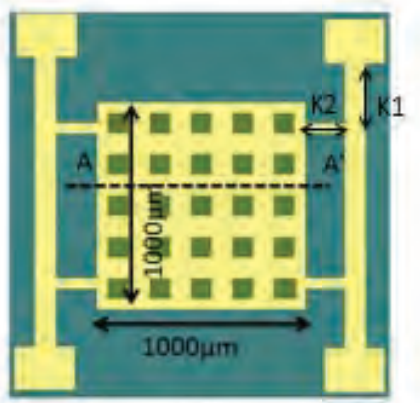

(a)

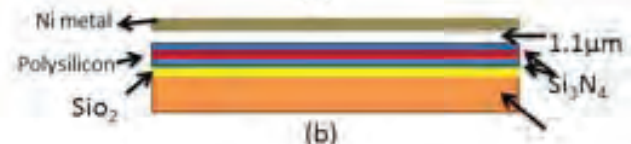

(b)

Fig.9(a) Layout of variable capacitor.(b).A-A' Cross sectional view of variable capacitor. 


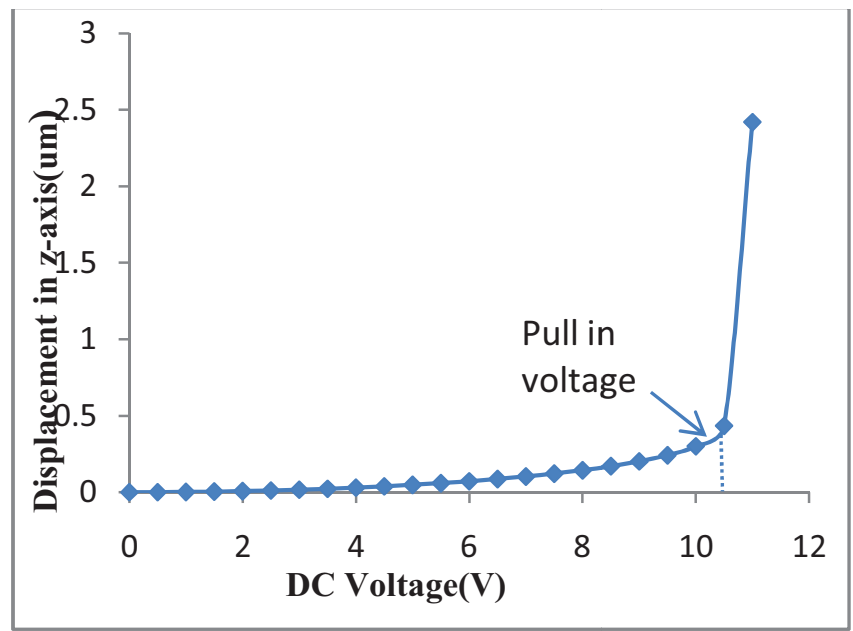

Fig. 10 Voltage vs displacement in z-axis plot.

Fig.10 shows that as voltage increases the gap between capacitor plates decreases due to which the change in capacitance increases. After $10.5 \mathrm{~V}$, there is sudden change in capacitance, that arises due to pull-in effect, which is difficult to calibrate. It is noted from the fig. 11 that a total change of about $3 \mathrm{pF}$ can be obtain from the proposed design of tunable capacitor.

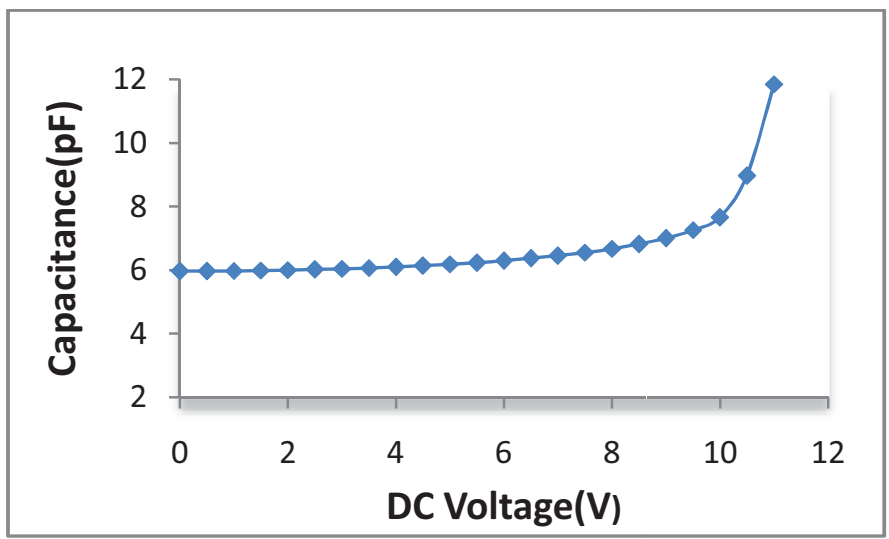

Fig. 11 Voltage vs change in capacitance plot.

\section{CONCLUSIONS}

A novel LLC resonant converter based on metal MUMPs with resonance frequency tuning has been proposed. The behavior of tuning capacitor has been through mathematical modeling and simulation. The micro-transformer is simulated in AC/DC module of COMSOL and MEMS based variable capacitor is simulated in Intellisuite. The design is implemented in commercially available standard process Metal Mumps which is a low cost reliable process. To improve magnetizing inductance and to avoid EMC interference NiZn ferromagnetic material with polymer is glued at the top of transformer coil. It is observed that $14.6 \mathrm{nH}$ magnetizing inductance and $48 \mathrm{nH}$ leakage inductance have been obtained from $3.6 \mathrm{~mm}^{2}$ transformer size at frequency of about $20 \mathrm{MHz}$. The total capacitance of about $1300 \mathrm{pF}$ has been achieved from the $12.25 \mathrm{~mm}^{2}$ fixed capacitor. The total variation of about $3 \mathrm{pF}$ has been achieved from the tunable capacitor at $10.4 \mathrm{~V}$.

\section{ACKNOWLEDGMENT}

This work is supported by Griffith University Australia under "Griffith University New Researcher Grant" research fund.

\section{REFERENCES}

[1] H. Choi, " Analysis and design of LLC resonant converter with integrated transformer”, IEEE, pp. 1630-1635, 2007.

[2] R. Bashirullah," Wireless Implants", IEEE microwave magazine, (2010), p.p.S14-S23.

[3] S. De Simone, C. Adragna, C. Spini, "Design guideline for magnetic integration in LLC resonant converters," International Symposium on power electronics, SPEEDAM, 2008, pp. 950-957.

[4] B. Lu, W. Liu, Y. Liang, F. C. Lee, "Optimal Design Methodology for LLC resonant converter", IEEE, 2006, pp. 533-538.

[5] N. Wang, T. O’ Donnel, R. Meere, F. M. Rhen, S. Roy, and S. Cian O' Mathuna," Thin-Film-Integrated Power Inductor on $\mathrm{Si}$ and its Performance in an 8-MHz Buck Converter.

[6] M. Mino, T. Yachi, A. Tago, K. Yanagisawa, and K. Sakakibara "Planar Microtransformer with Monolithically-integrated rectifier diodes for Micro-switching converters," IEEE Transaction on Magnetics, Vol. 32, no. 2, March 1996, pp. 291-295.

[7] N. Wang, T. O’Donnell, S. Roy, S. Kulkarni, P. Mccloskey and C. O' Mathuna, "Thin Film Microtransformer integrated on Silicon for Signal Isolation," IEEE Transactions on Magnetics, vol. 43, no.6, June 2007, pp. 2719-2721.

[8] R. Wu, J. K. Sin,” A novel Silicon-Embedded Coreless Transformer for Isolation DC-DC Converter Application". Proc. Of $23^{\text {rd }}$ International Symposium on power Semiconductor Devices \& IC's, San Diego, May 2011,pp.352-355.

[9] S.C. Mathuna, T. Donnell, "Magnetics on Silicon: An Enabling Technology for power supply on chip." IEEE Transaction on power electronics, vol. 20, no.3, May 2005, pp.585-592.

[10] K. Onizuka, H. Kawaguchi, M .Takamiya,” Stacked-chip Implementaion of on-chip buck converter for Power-Aware distributed power supply systems." IEEE, 2006. pp.127-130.

[11] P. Hazucha, G. Schrom, J. Hahn, B. A. Bloechel," A 233-M Hz 80\%$87 \%$ efficient four phase DC-DC converter utilizing air-core Inductors on package. 